\title{
Resources Construction and Teaching Application with Tsinghua University Network Course Platform
}

\author{
Jingren $\mathrm{CaO}^{1, \mathrm{a}}$ and Ping $\mathrm{Xin}^{1, \mathrm{~b}^{*}}$ \\ ${ }^{1}$ BeiHua University, Jilin City Longtan Hill Street No. 1, JiLin, China \\ 334916434@qq.com, a*359411897@qq.com
}

\begin{abstract}
Keywords: Network course platform; Teaching model; Performance evaluation; Excellent engineer training
\end{abstract}

\begin{abstract}
This article introduces how our Electrical-drive course group makes Resources Construction on the network-teaching platform of Tsinghua University, and how we use the platform to make the curriculum construction and the curriculum reform. Firstly, we introduce the main features and usage methods of the platform. Then we introduce the experience of using the platform to carry out teaching reform. Finally, we introduce the reference rules for students' performance evaluation after using the platform. Our course group applies the results of the reform to the two courses, "Fundamentals of motor drives" and "power electronic technology". From the contrast of the students' achievements before and after the curriculum reform, we can see that the platform plays an important role in improving the theoretical teaching effects and realizes the training of excellent engineers.
\end{abstract}

\section{Introduction}

Our university introduced the network course teaching platform of Tsinghua University five years ago, and has established a wealth of network teaching resources so far. The platform provides a convenient and fast construction environment for teachers to construct the network teaching resources for every course. The construction of platform adopts the idea of modularization, and all necessary projects for course construction are set up completely. Teachers can add learning materials for meeting the needs of teaching. And this can save much of teachers' time, because they can free themselves from putting too much energy for the construction of network platform environment. At the same time, the platform module is not single and rigid. If the teacher has its own ideas, the platform also provides teachers with the function of setting up their own user-modules. The Department of electrical engineering and automation which our course group subordinates to has devoted to training excellent and advanced engineers talents many years. Therefore, the reform of teaching model has been carried out continuously, and new and effective teaching methods have been sought. How to teach students in accordance with their aptitude, how to improve the teaching effect in the limited classroom teaching time, and how to strengthen the training of students' ability, thus questions have become the subject of continuous exploration. After using this network teaching platform to make the course reformation, our course group adjusts the teaching model and the teaching method promptly, and has obtained the encouraging result.

\section{Introduction of the Resources Construction on Network Teaching Platform}

Fig. 1 showed the modules contained by the network teaching platform. There are totally 16 teaching sub-modules. Here we integrate them into five main modules, which are the '1)curriculum guide module', the '(2)teaching resource module', the '(3)after-class communication module', the '(4)level test module', and the '(5)system management module'. 


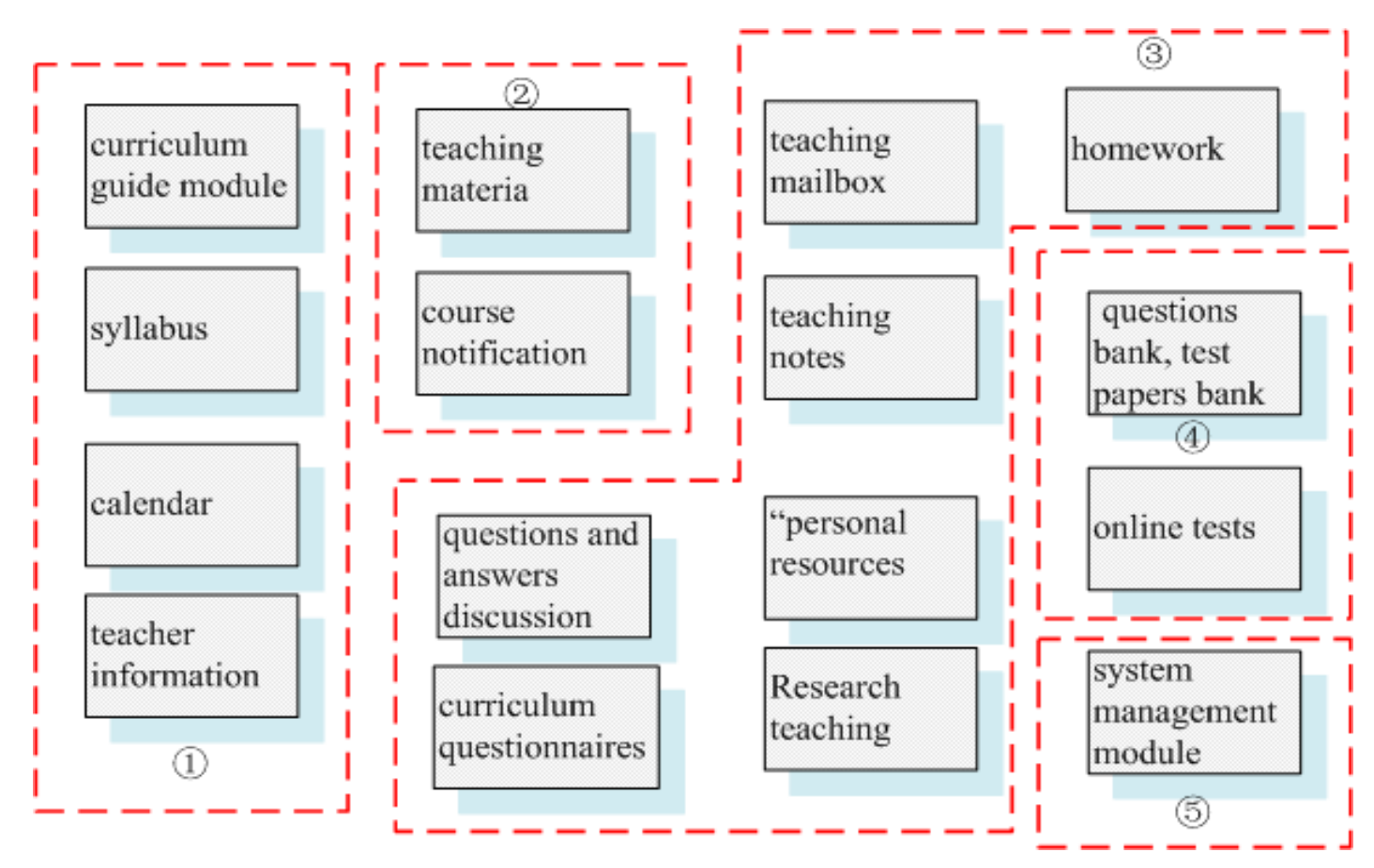

Figure 1. modules of the network teaching platform

Among them, the 'curriculum guide module' includes curriculum introduction, syllabus, calendar, teacher information and so on. This section can help students quickly catch the purpose of this course, learning content, learning process, learning plans and so on. The course group has added relevant information to the module, in particularly focusing on the role of the course in the professional. Through the guiding information, we can instruct teachers who undertake the course to have uniform standards for reference. Then everyone in our group can have the same teaching target of training for excellent engineers. Teaching calendars provide directions for students to preview ahead of time. They can also set up their own study plans. Teacher information provides ways for students to contact teachers. [1]

Then what is the function of the 'teaching resource module'? First is the teaching material releasing, including lecture notes, and simultaneous teaching PPT, key points and difficulties of knowledge, and typical examples explaining, reference materials, small teaching video, as well as the preparation materials of the experiment class. These materials are closely linked to the classroom teaching. Second one is the course notification, including preparation request, schedule adjustment, experimental arrangements. The third is the assignments required to complete and the answers. All mentioned above are conventional resources. [2]In order to achieve the goal of excellent engineer training, the curriculum group also supplements the extended knowledge resources related to the teaching content. Outstanding engineers should have not only a solid theoretical foundation, but also have enough analysis ability and practical ability to overcome the difficult work independently. In view of this training objective, the basic knowledge which is needed to learn the course is included in the resources. It also contains relevant enhancement knowledge. These learning materials are integrated by teachers through their own knowledge, skills, with which students of different levels can make supplement learning. For example, students who are weak in foundation can find the materials for study here directly, while the students with high learning efficiency can expand their studies here, too.

The 'after-class communication module' includes "questions and answers discussion", "curriculum questionnaires" (feedback from students on teaching effectiveness, teachers can adjust the teaching methods and teaching progress according to the message here), "teaching mailbox" and so on. Teachers and students can make timely and effective communication through the platform provided by this 
module, so as to achieve the best combination of teaching and learning. In addition, this main module also contains two sub-modules of "teaching notes" and "personal resources". The former is used by teachers to reflect on the content and effect of each lesson, and summarize personal experience, and the browsing authority of this section is limited to the teachers only. Reading this part can enlighten the teaching work in the future. "Personal data" is a summary of the learning resources from the students or the teachers themselves.[3-4]

The 'level test module' includes questions bank, test papers bank, and online tests to help students consolidate and strengthen the knowledge they learned.

The 'system management module' includes the function of addition of the enrolled students list, and the function of addition of the teachers list. The administrator can sets the permissions for each person (browse, modify, upload data, etc.) in the list.

As described above, The platform is reasonable and comprehensive。Young teachers who have just been employed can develop good teaching ideas and teaching habits if they use the platform. Our course group is just on such a platform to construct our own network teaching resources. In the information age, Internet resources are rich and colorful, and there are many materials related to the course. However, those resources are true and false, and multifarious, repetitive. They are obviously lack of systematic, authoritative and targeted. Students should spend a lot of energy on content differentiation, but their professional level is limited. It is not professional for them to start this kind of work. The resources on our platform are carefully integrated by the teachers of the course group, and they are closely related to the training objectives and teaching process of the class. Students can easily obtain the required learning resources here, with half the effort.

\section{Reform of Teaching Model Based on Classroom Teaching with Network Teaching as Auxiliary}

Traditional teaching is based on the model of single classroom instruction. No matter classroom instruction, pre-class preparation, or after-class review, the communication between teachers and students is limited to the classroom-time. After class, the teacher left the classroom quickly. In order to communicate with teachers, students must make an appointment for time and place. That is very inconvenient, and the problem can not be solved in time. In view of the above problems, our course group makes the teaching model reform as "classroom teaching with network teaching as auxiliary ". Now we explain how we implement this teaching model and its characteristics.

As far as classroom instruction is concerned, our teachers will put the main time of instruction in key and difficult knowledge, because the network provides enough resources and guidance for students to prepare lessons before class. In the teacher's request, students first finish the network environment learning before learn in the classroom. Here they mainly use the "curriculum guide module" and the "teaching resource module". Students read and understand the prescribed materials, complete a series of tasks required. In class-time, the teacher should ask questions first or ask questions during the course of his (her) lecture. Teachers only spend a lot of time explaining things on very important and difficult questions to understand. From the use of this model, we can see that the teaching process has accelerated noticeably, and the teaching effect is well.

Finally, we should talk about the problem of after-class communication. First of all, we know that necessary exercises can help students understand the knowledge and skills more deeply, but the classroom time is limited and the teaching information is very large. In the past, there did not give the university teachers and students sufficient time to explain the exercises. The common situation is that homework is left and corrected, but there is no time to explain. Problems can not be cleaned up in time, and more and more, finally hinder learning. Our course group takes full advantage of the "after-class communication module" to collect and sort out the students' problems timely, and then we made small videos of explaining and uploaded them to the teaching platform for students in doubt to use. In this way, not only can students' question be answered in time, but also can teachers' repeated labor be reduced. In the other hand, because of the introverted personality of the Chinese people, students often reluctant to take the initiative to communicate with teachers face to face. If they do not keep up with the teacher, they will choose not to say it. We use the "Curriculum Questionnaire" function, require students to fill 
out the teaching effect questionnaire, and to master the learning characteristics of each student and their different ideas, in the light of which we adjust the teaching process and teaching methods to improve teaching effect.

\section{Student Score Evaluation}

We believe that the initiative of students is not as good as that of graduates because of the different purposes of learning. Students want to pass the examination, and finally obtain the diploma. This goal is vague, and is too long to be realized, so that slacking is easy to emerge. While after graduate, if one does not learn, he can not complete the task. And the effect of how the job be completed is directly linked to the wages and his survival. Graduate must raise his technical level, or he will soon be eliminated by society. This encourages them to learn actively. Then, how to arouse students' enthusiasm for learning? We think that the methods of score evaluation have great influence.[5-6]

The assessment of the course is still based on the classroom-examination, taking into account online performance.

In order to avoid the drawbacks of a scoring evaluation depending on only one test paper, the classroom-examination takes the principle of evaluate the scores from several unit examinations. In order to reduce the teacher's burden on going over examination papers, the examination adopts the form of unified on-line answering in the computer room. We use the "level test module" to complete this work. Firstly, teachers constructed the questions bank and the test papers bank. Then teachers use the "online tests" sub- module to construct the unit test paper. As long as the question setting strategy is set up in this sub-module, the system will automatically combine the exercises according to the requirements, thus a random test paper is formed for each student. The contents of the questions bank and the test papers bank are set up for students to read and exercise. Because the unit exam is closely related to the knowledge that has just been studied, it can strengthen the students' learning timely. This kind of review for unit test is better than the concentrated one before final exam.[7]

A great engineer must have effective data access ability and information integration skills. To this end, we added resources contribution scores to the scoring items. If the student's personal resources are well arranged, they can be sent to the teaching mailbox for screening. We have chosen the better ones to upload to the public resource platform for other students to learn. This part of the contribution will be handed down generation after generation. All resources must be signed, in order to give thanks to the senior's labor. This part of the contribution will also be translated into scores. The sense of achievement can not be measured by scores.[8-10]

\section{Conclusions and Prospects}

First of all, we applied this model to the teaching of the course "Fundamentals of motor drive". Later, after summing up experience we popularized the achievements of reform. The same teaching model was implemented in course "power electronic technology". The teaching effect of the two courses has all been improved. Through the reform, the initiative of the students has been improved, both in the preview stage, the learning stage, and in the review stage. Teachers guide students to use the learning resources of the teaching platform. Students have developed good study habits. Because the resources are abundant, and are very close to the teaching content, so that students can use the learning materials easily. Assessment methods make students no longer be an "Examination shock worker", but to be ones that truly master the knowledge in the heart. Frequent interaction between students and teachers online and offline, promotes active academic atmosphere, and achieves gratifying scene of teacher and the student making progress together. 


\section{Acknowledgements}

This research was financially supported by the Education and teaching research topics of Beihua University (XJYB2016016); The Education and teaching research topics of Beihua University (XJQN2017030).

\section{References}

[1] G.N. Liu: Design and Implementation of the Network Course Based on Moodle Are Explored, Modern Educational Technology, 2008, p.56-59.

[2] Y.T. Qiao, Q.L. Bao and L. Zeng: A Research on Innovation and Inspiration of Higher Education Management Mode in the "Internet +" Era, Journal of Higher Education Research, Vol. 38 (2015) No.4, p.83-87. (In Chinese)

[3] X.P. Zhang, D.H. Wu: Construction and Practice of P.E. Network Course Based on Module Theory in University, Springer Netherlands, 2014, 269: 3103-3110.

[4] L. Ma, X. Li, L. Liu, and S. Wu: Analysis of Theory and Practice of Network Course Construction and Application, International Conference on E-business \& E-government, 2011, p.1-3.

[5] Q. Y. Zhang: Investigation and Research on the Assessment of College Students' Normal Grades, Science and education Digest, Vol. 30 (2013) p.50-51. (In Chinese)

[6] H. Zheng, Y.N. Du, X.B. Qiao: Problems and Countermeasures in the Evaluation of College Students' Achievements, Science and Education Guide, Vol.32 (2015), p.165-167. (In Chinese)

[7] Y.L. Yang, K. Du, L.Y. Wang: Research on Evaluation Index System of Teaching Effectiveness of Space Network Course, Teacher of China, Vol.1( 2014), p. 33-35. (In Chinese)

[8] X.F. Cai: Exploration on the Teaching Reform of "Electrical Machinery and Drag" Course under the Mode of Applied Talents Training, Science and Education Digest, Vol.25 (2015), p.54-55. (In Chinese)

[9] J. Xu, A. A. Zhang, and W. M. Zhao:Teaching Reform of Electrical Engineering Course Based on Training Target of Excellent Engineers, College education, Vol.1(2017), p.77-78. (In Chinese)

[10] B.Y. Luo:Exploration of the Teaching Method of Electrical Machinery Based on the Training of 3 Ecellent Engineers, Education and Teaching Forum, Vol.33(2016), p.195-196. (In Chinese) 